\title{
Biodiversidade e conhecimentos tradicionais
}

\author{
Priscila Pereira de Andrade* \\ priscila_andrade@hotmail.com
}

\section{RESUMO}

Os conhecimentos tradicionais são informações de comunidades indígenas ou de comunidades locais que apresentam valor real ou potencial associado ao patrimônio genético. Contudo, nem sempre o conhecimento tradicional é reconhecido e protegido da forma que deveria ser. Este artigo tem como objetivo apontar os principais instrumentos legais utilizados, internacionalmente e nacionalmente, na proteção da biodiversidade e dos conhecimentos tradicionais relacionados a ela. Assim, serão analisados, entre outros, a Convenção sobre Diversidade Biológica e o Acordo sobre os Aspectos dos Direitos de Propriedade Intelectual Relacionados ao Comércio.

Palavras-chave: Conhecimento tradicional; Biodiversidade; CDB (Convenção sobre Diversidade Biológica); TRIPS (Acordo sobre os Aspectos dos Direitos de Propriedade Intelectual Relacionados ao Comércio).

\section{Biodiversity and traditional knowledge}

\section{ABSTRACT}

Traditional knowledge are information from indigenous communities or local communities that represent real or potential value associated to genetic heritage. However, not always traditional knowledge is recognized and protected appropriately. This article has the objective of pointing out the main legal instruments used internationally and nationally to protect biodiversity and traditional knowledge related to it. Thus the Convention on Biological Diversity and the Convention about Trade Related aspects of Intellectual Property Rights will be analyzed.

Key words: Traditional knowledge; Biodiversity; CBD (Convention on Biological Diversity); TRIPS (Trade Related aspects of Intellectual Property Rights).

\footnotetext{
* Acadêmica do curso de Direito do Centro Universitário de Brasília (UniCEUB); bolsista do CNPq; bolsista do PICUniCEUB; pesquisadora do Grupo de Estudos em Direito Internacional e Meio Ambiente (GERIMA).
} 


\section{INTRODUÇÃO}

No âmbito internacional, a questão da biodiversidade já aparecia no "Relatório Brundtland”, da Comissão Mundial sobre Meio Ambiente e Desenvolvimento. Contudo, um dos eventos mais importantes realizados internacionalmente foi a Conferência das Nações Unidas sobre Meio Ambiente e Desenvolvimento (CNUMAD 92, também conhecida como Rio 92), em que foram firmados acordos sobre o uso sustentável da biodiversidade. A CNUMAD 92 deu origem à Agenda 21, um cronograma mundial para o desenvolvimento sustentável internacional, e à Convenção sobre a Diversidade Biológica (CDB).

A Convenção sobre a Diversidade Biológica entrou em vigor em 29 de dezembro de 1993. O termo biodiversidade ficou conhecido como a variabilidade de organismos vivos de todas as origens e os complexos ecológicos de que fazem parte, compreendendo a diversidade dentro de espécies, entre espécies e de ecossistemas (PÉRET DE SANT’ANA, 2002 p. 29). Contudo, o conceito passou por profunda transformação, abrangendo, além de mera variabilidade das espécies, a diversidade genética e ambiental. A biodiversidade, como conjunto de recursos biológicos e genéticos, tornou-se uma aposta econômica tanto por parte de países detentores de tecnologia, como os detentores de biodiversidade, em sua maioria, países em desenvolvimento.

O Brasil apresenta a maior biodiversidade do mundo graças à extensão territorial e à posição geográfica. Estima-se que o país possua entre 15\% e 20\% do número total de espécies do mundo, superior a 55 mil espécies descritas, cerca de $22 \%$ do total mundial. ${ }^{1}$ A diversidade cultural também impressiona. São 206 culturas indígenas que falam mais de 160 línguas, além de diversas comunidades locais, como seringueiros, quilombolas, ribeirinhos e praticantes do candomblé que acumularam conhecimento no uso sustentável da biodiversidade (MANCINI 2002).

O aumento do mercado mundial de produtos biotecnológicos ${ }^{2}$ e farmacêuticos com origem biológica (derivados de vegetais, animais, insetos e outros) evidenciou a importância do

1 Ver MINISTÉRIO DO MEIO AMBIENTE. Informações retiradas do site: $<$ http://www.mma.gov.br/port/sbf/chm/biodiv/brasil.html>. Acesso em: 20 fev. 2006.

2 "Biotecnologia constitui-se em qualquer técnica que use organismos vivos - ou parte de organismos para a criação ou modificação de produtos; para o melhoramento de plantas ou de animais ou para o desenvolvimento de microorganismos para usos específicos” (PÉRET DE SANT’ANA, 2002, p.30). 
material genético neste novo século. Possuir ou ter acesso à biodiversidade tornou-se algo estratégico. Entretanto, a riqueza e a variedade da biodiversidade podem significar novo problema: como encontrar, na grande quantidade de material genético, o que pode gerar um produto inovador?

A bioprospecção, ou seja, o método de localizar, avaliar e explorar a diversidade de vida de um local com o objetivo de encontrar recursos genéticos e bioquímicos para fins medicinais e comerciais, aumentou consideravelmente nos últimos anos, com a aplicação de novas tecnologias científicas. Um exemplo é o desenvolvimento de fármacos e cosméticos com a biodiversidade de plantas.

A etnobotânica, ou o estudo dos conhecimentos botânicos e de utilização de plantas pelas comunidades tradicionais, é uma ciência cada vez mais utilizada como orientadora de atividades de bioprospecção. No entanto, com o intuito de obter maior lucro por meio dos resultados de pesquisas, cientistas e firmas que realizam a bioprospecção baseada em etnoconhecimento nem sempre reconhecem e valorizam o conhecimento de comunidades locais.

A proteção dos conhecimentos tradicionais, das inovações e dos direitos indígenas e de pessoas de comunidades locais, na maior parte das vezes, nem sequer é mencionada. As formas de proteção de conhecimento tradicional existentes não são aplicáveis ou eficientes. Elaborar novas maneiras de proteção é crucial, tendo em vista que esses conhecimentos são ponto-chave para a atividade de bioprospecção.

O presente artigo tem como objetivo analisar questões relacionadas às definições de conhecimento tradicional e povos indígenas, tendo em vista o surgimento do "mercado biotecnológico” e o uso do conhecimento tradicional associado à biodiversidade. Na primeira parte, serão relacionadas normas e convenções existentes, nacionais e internacionais, como a Convenção sobre Diversidade Biológica e os tratados referentes à propriedade intelectual. Serão traçadas linhas gerais sobre a legislação interna do Brasil, formas e pontos essenciais para criação de alternativa de proteção de tal conhecimento, ou seja, uma proteção sui generis. Serão analisadas as etapas do processo de bioprospecção e as opiniões indígenas relacionadas ao tema. Na segunda parte, serão definidos os contratos existentes para os recursos genéticos. Por fim, serão especificadas as formas de acesso e divisão de benefícios que vem ocorrendo nesses últimos anos. 


\section{CONCEITOS E NORMAS RELEVANTES}

\subsection{Conhecimento tradicional}

A noção de conhecimento tradicional, conhecimento indígena e povos indígenas tem sido indispensável em debates internacionais relacionados ao desenvolvimento sustentável com base na biodiversidade. Embora muito esforço tenha sido empregado a fim de conceituar esses três tópicos, não existem definições universalmente aceitas.

A Convenção $n^{\circ} 169$ da Organização Internacional do Trabalho (OIT), que faz referência a povos indígenas e pessoas tribais de países independentes, considerou povos indígenas como:

“Art 1 - Pessoas de países independentes que são conhecidas como indígenas por serem descendentes de populações que habitavam o país, ou região geográfica, ao qual o país pertencia no período da colonização e que independente de sua posição legal, conserva um pouco ou toda sua instituição social, econômica, cultural e política” (OIT.).

Para essa convenção, pessoas tradicionais são aquelas que detêm costumes nãoescritos, crenças e rituais transmitidos de geração em geração, não precisam necessariamente ter ocupado o território antes da colonização, podendo até ser imigrantes. Com isso, pessoas tradicionais não são necessariamente indígenas, mas povos indígenas são tradicionais.

Em nosso e em outros países, fala-se em povos indígenas, ao passo que, na Austrália, por exemplo, a forma genérica para designá-los é aborígine. Indígenas ou aborígines, ambos os termos significam “originário de determinado país, região, ou localidade”. Nativos e autóctones são outras expressões utilizadas, ao redor do mundo, para denominar esses povos. Independentemente da nomenclatura usada, todos os povos indígenas, aborígines e autóctones apresentam, em comum, o fato de cada qual se identificar como coletividade específica organizada antes da colonização, distinta de outras com as quais convive e, principalmente, do conjunto da sociedade do país onde está. É importante notar que existem autores, como Posey e Dutfield (1996), que não fazem distinções quanto a povos indígenas e pessoas tradicionais e 
utilizam esses conceitos de maneira permutável. Contudo, acreditamos que tal distinção seja indispensável.

O termo tradicional está relacionado à tradição. Segundo Bueno (1996), tradição é “a transmissão oral de lendas ou narrativa; transmissão de valores espirituais de geração em geração; conhecimento ou prática proveniente de transmissão oral ou de hábitos inveterados; recordação; memória; costume, uso”. Uma relação similar pode ser feita entre conhecimento tradicional e conhecimento indígena. O conhecimento tradicional é aquela sabedoria convencional relacionada à cultura em si ou ao ecossistema local no qual existe, sendo assegurado a pessoas de culturas diferentes. Por outro lado, o conhecimento indígena é garantido e usado por pessoas que se identificam como índios de determinado local por apresentarem cultura diferente da população pós-colonização existente. Assim, o conhecimento indígena pode ser uma categoria do conhecimento tradicional, mas o conhecimento tradicional não é necessariamente indígena.

Desta maneira, o conhecimento tradicional constitui práticas, conhecimentos empíricos e costumes passados de pais para filhos e crenças das comunidades tradicionais que vivem em contato direto com a natureza, ou seja, é o resultado de um processo cumulativo, informal e de longo tempo de formação. É tido como patrimônio comum do grupo social. Tem caráter difuso, pois não pertence a este ou aquele indivíduo, e sim a toda a comunidade.

É comum associar a origem de um conhecimento tradicional a uma comunidade tradicional, no entanto é possível que a origem desse conhecimento seja de uma cidade ou, até mesmo, de uma única pessoa. Por exemplo, se existe uma planta em determinada localidade, na qual somente as pessoas da cidade mais próxima têm conhecimento sobre sua eficiência medicinal, trata-se de conhecimento próprio daquela cidade, por isso tradicional. Não se pode, assim, generalizar que a origem do conhecimento tradicional seja sempre de uma comunidade local, podendo ser obtido em uma cidade ou vilarejo.

É preciso atentar para que o conhecimento tradicional seja um conceito mais amplo que conhecimento tradicional associado à biodiversidade, pois este último é apenas uma parte daquele primeiro, que envolve práticas culturais, como, por exemplo, a arte. O conhecimento tradicional relativo à diversidade biológica é indispensável para a conservação da biodiversidade global assim como para seu uso sustentável. A importância desse conhecimento foi reconhecida 
pela primeira vez na Conferência das Nações Unidas para o Meio Ambiente e Desenvolvimento, sediada no Rio de Janeiro em 1992.

De acordo com a Convenção sobre Diversidade Biológica (CDB), o acesso e o uso do conhecimento tradicional devem ser realizados com o consentimento prévio das comunidades, e os benefícios oriundos dessa utilização devem ser divididos de forma eqüitativa. Veremos, nos tópicos subseqüentes, como a Organização Mundial do Comércio (OMC) possui estrutura jurídica que pode ser considerada contrária à exigência do consentimento prévio das comunidades para o uso de seus conhecimentos, ao tentar estabelecer regras de direitos individuais e propriedade intelectual aos conhecimentos.

\subsection{Conhecimento tradicional como propriedade intelectual}

Até 1992, os recursos e os conhecimentos tradicionais eram vistos como patrimônio comum da humanidade. Não existiam normas internacionais ou nacionais que regulassem o acesso aos recursos genéticos. Com isso, houve aumento no uso dos recursos biológicos dos povos tradicionais e rápido esgotamento de recursos do meio ambiente. Nesse cenário, os países em desenvolvimento compreenderam que a biodiversidade era uma fonte de recursos que poderia financiar seu desenvolvimento. Assim, foi colocada em questão a noção de patrimônio comum da humanidade, em favor do conceito de patrimônio nacional.

Definir a forma de proteção e utilização legal para os conhecimentos tradicionais que conserve a biodiversidade e promova o desenvolvimento sustentável é um dos assuntos mais debatido nos fóruns internacionais sobre meio ambiente e propriedade intelectual. A propriedade intelectual e a propriedade industrial são os meios comumente utilizados para proteger tanto os recursos biológicos como o conhecimento tradicional. No entanto, esse não é o modo mais viável de proteção.

A propriedade intelectual visa à posse de um recurso particular que não se consegue obter na natureza. Geralmente, envolve a proteção de alguma invenção criada pelo ser humano. Existem várias formas de propriedade intelectual que podem ser aplicadas a processos e produtos farmacêuticos, tais como, proteção de cultivares, patentes, segredo industrial, contratos. Contudo, 
nos contratos de bioprospecção, as formas de proteção intelectual mais utilizadas são as patentes e a proteção de cultivares.

O direito de propriedade intelectual pode ser visto como um direito de exclusividade concedido pelo Estado para comercialização de determinado bem. No atual sistema de patentes, é necessário que o objeto a ser patenteado seja novo e individual, o que não é verificado no tocante ao conhecimento tradicional que é transgeracional e coletivo. Definir quem seria o beneficiário no caso das comunidades locais é um ponto bastante polêmico. A titularidade incerta seria coletiva, comunitária, ou exercida por agências governamentais? Seria o chefe da tribo indígena ou toda a comunidade conhecida como beneficiário? De acordo com as questões levantadas, fica evidente que tal sistema de propriedade intelectual deverá ser reformulado para que ocorra a devida proteção dos conhecimentos tradicionais.

Os críticos argumentam que os direitos de propriedade intelectual são uma ameaça à biodiversidade, por limitar o acesso aos recursos e aos produtos deles derivados. Os que estão a favor argumentam que os direitos de propriedade intelectual encorajam a transferência de tecnologia, que poderá ser estratégia para a partilha eqüitativa de benefícios. Nesse contexto, verificamos os países do Norte, que apóiam os direitos de propriedade intelectual como incentivo à transferência de tecnologia, e os países do Sul, que consideram poder a propriedade intelectual limitar o acesso e o uso sustentável da biodiversidade.

A Convenção sobre Diversidade Biológica e o Acordo sobre os Aspectos dos Direitos de Propriedade Intelectual Relacionados ao Comércio (TRIPS) são algumas das referências mais utilizadas no tocante ao conhecimento tradicional e à propriedade intelectual, respectivamente. Cabe, no entanto, apontar outros instrumentos internacionais que reconhecem os direitos culturais das comunidades indígenas e asseguram proteção à sua diversidade cultural: a Convenção nº169 da Organização Internacional do Trabalho e a Resolução 1990/27 do Grupo de Trabalho sobre Populações Indígenas criado em 1982, pelo Conselho Econômico e Social da ONU estão entre os mais importantes. O crescente número de ONGs (Organizações não-governamentais) e instituições particulares na defesa desses direitos também tornou-se evidente.

\subsection{Convenção sobre a diversidade biológica $x$ acordo sobre os aspectos dos direitos de propriedade intelectual relacionados ao comércio}


Para compreender melhor o conflito de interesses advindos do uso e da conservação da biodiversidade, duas instâncias internacionais serão analisadas: A CDB e o acordo TRIPS.

Segundo Egler (2002, p. 41), o Programa das Nações Unidas para o Meio Ambiente (PNUMA) preparou a Convenção sobre Diversidade Biológica no sentido de defender a conservação de espécies e o uso sustentável, com base nos princípios desenvolvidos pelas organizações não-governamentais internacionais, como a União Internacional de Conservação da Natureza (UICN) e o Instituto de Recursos Mundiais (WRI). Um dos princípios da Convenção era ter a biodiversidade como patrimônio comum da humanidade, ou seja, deveria ser de livre acesso para todos.

Entretanto, como visto anteriormente, os países subdesenvolvidos perceberam a enorme influência que a diversidade biológica teria no seu desenvolvimento. Por isso, exigiram que a Convenção sobre Diversidade Biológica não se limitasse aos aspectos de conservação strictu sensu e pressionaram as negociações no sentido de obter uma convenção baseada no regime de royalties, em troca da exploração dos recursos genéticos pelos países industrializados. Assim, a convenção teve suas características modificadas, passando a ter princípios e regras gerais, um tratado de desenvolvimento sustentável aplicado à conservação dos recursos genéticos, deixando de ser uma convenção sistematizadora e conservacionista.

A biodiversidade não era mais reconhecida como patrimônio comum da humanidade, e sim como preocupação comum da humanidade. Os Estados passaram a ter direito soberano sobre seus recursos genéticos, não havendo mais acesso ilimitado à diversidade biológica de determinado país.

A Convenção sobre Diversidade Biológica contém estipulações importantes relacionadas aos direitos das comunidades tradicionais e indígenas, reconhecendo o papel essencial que desempenham na conservação da biodiversidade, principalmente no tocante ao acesso aos recursos genéticos e à repartição de benefícios. Os dispositivos e os princípios dessa convenção apresentam como objetivos principais: a conservação da diversidade biológica, o desenvolvimento economicamente sustentável dos países do terceiro mundo no uso da biodiversidade, uma divisão dos benefícios resultantes de forma justa e eqüitativa. Tanto o 
preâmbulo como os artigos dessa convenção citam a importância do conhecimento tradicional e dos povos tradicionais.

Os artigos $10(\mathrm{c})^{3}, 18(4)^{4}, 19^{5}$ e $8(\mathrm{j})^{6}$ fazem referência aos direitos de pessoas de comunidades locais e de povos indígenas. O artigo 10(c), por exemplo, cita que cada parte contratante da referida convenção deve proteger e encorajar o uso costumeiro dos recursos biológicos de acordo com as práticas culturais e tradicionais, por serem compatíveis à conservação e ao uso sustentável da biodiversidade. O artigo 18(4) cita que toda tecnologia deve incluir as tecnologias tradicional e indígena. O artigo 19 reforça a questão da compensação eqüitativa pelo acesso aos recursos genéticos.

O artigo 8(j), o mais relacionado ao tema, estabelece que os países signatários devem “respeitar, preservar e manter o conhecimento, as inovações e as práticas das comunidades locais e das populações indígenas com estilo de vida tradicional relevante à conservação e à utilização sustentável da diversidade biológica", bem como "incentivar sua mais ampla aplicação com a aprovação e a participação dos detentores desse conhecimento, inovações e práticas”, e "encorajar a repartição de benefícios oriundos da utilização desse conhecimento, inovações e práticas”.

A CDB reconhece os direitos de propriedade intelectual, entendendo que devem promover, e não comprometer, os objetivos da convenção. Não existem, na convenção, dispositivos relacionados diretamente à propriedade intelectual, mas apenas normas genéricas. A CDB deixa a proteção dos conhecimentos, das inovações e das práticas tradicionais à discrição de cada parte contratante. O artigo 8(j) não trata de proteção do conhecimento tradicional, mas menciona que cada parte deve preservar, respeitar e mantê-lo. Segundo Varella (1998), a Convenção sobre a Diversidade Biológica estabelece que: “[...] os contratos envolvendo propriedade intelectual devem respeitar as tradições regionais, como a cultura das tribos indígenas e das comunidades locais, bem como trazer mecanismos eqüitativos de divisão de benefícios entre as partes envolvidas”.

A Conferência das Partes (COP) é um órgão da CDB que reúne os países signatários da convenção, onde são realizadas reuniões sobre o detalhamento da convenção. Durante a $4^{\circ}$

\footnotetext{
${ }^{3}$ ANEXO 1

${ }^{4}$ ANEXO 2

${ }^{5}$ ANEXO 3

${ }^{6}$ ANEXO 4
} 
Conferência das Partes da Convenção sobre Diversidade Biológica, realizada em Bratislava, na República Eslovaca, os países signatários decidiram criar um grupo de trabalho ad hoc com a incumbência de propor medidas prioritárias e um programa de trabalho visando a formas apropriadas de proteção ao conhecimento tradicional associado à biodiversidade. Contudo, a CDB é tratada como soft norm ${ }^{7}$, necessitando, assim, que cada país regulamente o tema com leis nacionais.

Apesar dos diversos esforços, a CDB ainda não tem seus princípios colocados em prática porque empresas multinacionais e instituições de pesquisa apóiam-se normalmente em outro acordo internacional, o Acordo sobre os Aspectos dos Direitos de Propriedade Intelectual Relacionados ao Comércio (TRIPS), para explorar recursos biológicos em outros países. Os dispositivos da CDB que defendem a proteção dos conhecimentos tradicionais não são incorporados aos previstos pelo TRIPS, ocasionando indevida forma de proteção desses conhecimentos.

O acordo TRIPS define padrões de proteção para os direitos de propriedade intelectual nos 149 países-membros da OMC (Organização Mundial do Comércio) e é baseado na não-discriminação e na eliminação de barreiras comerciais. O artigo do acordo TRIPS que mais tem gerado polêmica em relação aos dispositivos da CDB é o 27.3(b) ${ }^{8}$, que determina os paísesmembros deverem proceder à proteção patentária sobre microorganismos e processos microbiológicos, podendo excluir plantas e animais de suas leis.

Para o Brasil, assim como para vários países em desenvolvimento, a aplicação deste artigo deve ocorrer de forma coerente com a Convenção sobre Diversidade Biológica. Por isso, o artigo 27.3 (b) do acordo TRIPS deve ser reformulado com a finalidade de excluir o patenteamento de todos os organismos vivos, incluindo animais, plantas, microorganismos e partes destes, bem como qualquer processo que faça uso dessas partes. Nesse sentido, políticos e diplomatas devem assumir posição estável e desenvolver propostas concretas para evitar o patenteamento de organismos vivos e assegurar a proteção dos conhecimentos tradicionais e o direito das comunidades locais sobre os recursos biológicos.

\footnotetext{
${ }^{7}$ No Direito Internacional existem normas que são menos cogentes, menos obrigatórias, cujo nível de interpretação é mais subjetivo. Essas normas são conhecidas como Soft norms.

${ }^{8}$ ANEXO 5
} 
Ao contrario das reuniões da Conferência das Partes da CDB, as reuniões do Conselho para o acordo TRIPS e do Comitê de Comércio e Meio Ambiente (CTE) não são abertas ao publico. A OMC prefere negociar suas decisões por consenso e a portas fechadas. O CTE tem sido um fórum de discussão da OMC. Das questões levantadas no CTE, de interesse na relação CDB e OMC, constam a proteção dos direitos sobre os recursos biológicos e a partilha de benefícios provenientes do patenteamento de produtos derivados desses recursos, como os direitos das populações tradicionais, os direitos de propriedade intelectual sobre o desenvolvimento, o acesso e a transferência de tecnologias.

Na negociação do acordo TRIPS, já existiam partes em controvérsia. De um lado, estavam os países desenvolvidos, como os Estados Unidos, querendo total proteção patentária sobre todas as áreas de tecnologia; do outro, estavam os países em desenvolvimento, lutando contra a inclusão dos direitos de propriedade intelectual nas convenções sobre o comércio mundial, alegando que economias diferentes necessitam de instrumentos diferentes para estimular a inovação. Esses países acreditavam que, com o estabelecimento de normas de propriedade intelectual, as empresas transnacionais de países desenvolvidos beneficiar-se-iam. Existia, ainda, a opinião européia, que não aceitava patentes sobre variedades de plantas e animais. A solução encontrada foi utilizar a Convenção Européia de Patentes como modelo para a formulação do artigo 27.3(b).

O artigo 27.3(b) seria revisado quatro anos após a entrada em vigência do Acordo TRIPS, isto é, em 1999. A esperança de mudanças no acordo TRIPS pelos países subdesenvolvidos estava relacionada à falta de parâmetros para implementação de um "sistema sui generis de proteção efetivo”. A questão de divisão de benefícios também deveria ter sido modificada, uma vez que o acordo TRIPS não oferecia qualquer proteção, mas acentuava o movimento de biopirataria. No entanto, essa revisão foi uma decepção para os países subdesenvolvidos, pois poucos interesses foram alcançados.

Em setembro de 2000, uma nova reunião foi realizada com novas propostas por parte da Índia, do Brasil e do grupo africano, com o objetivo de pressionar o conselho da OMC sobre questões, como biodiversidade, conhecimento tradicional, divisão de benefícios, entre outros. Houve, também, explica Albagli (1998, p. 35) uma forte demanda para a conciliação entre a CDB e o acordo TRIPS. As propostas do Brasil incluíam a divulgação da fonte do material genético, a 
divulgação do conhecimento tradicional usado na obtenção do material, a mostra de evidência do consentimento do governo, das comunidades locais e indígenas e a garantia de divisão justa e eqüitativa de benefícios (PÉRET DE SANT’ANA, 2002, p. 36).

Contudo, muito pouco tem sido alcançado por parte dos países subdesenvolvidos no âmbito da OMC. Percebemos que o principal objetivo da OMC com o acordo TRIPS é, mais uma vez, ampliar o comércio global. Por isso, continua sendo indispensável nova revisão do Acordo TRIPS e, principalmente, do artigo 27.3(b). O atual texto da TRIPS, além das ambigüidades, é resultado de um acordo entre países desenvolvidos, sem qualquer consideração relevante aos interesses dos países do terceiro mundo e aos princípios da CDB.

\section{4 Instrumentos legais aprovados e em discussão no Brasil}

Existem leis e artigos da Constituição Brasileira que regulamentam o tema. Primeiramente, cabe apontar o caput do artigo 225 da Constituição Federal, que reforça ser o meio ambiente ecologicamente equilibrado um bem de uso comum do povo e essencial à qualidade de vida sadia, impondo-se ao poder público e à coletividade o dever de defendê-lo e de preservá-lo para as presentes e futuras gerações.

Quanto aos instrumentos legais infraconstitucionais, isto é, leis federais e decretos-lei, podemos apontar como os mais importantes: Lei $n^{0}$ 7.347, de 24 de julho de 1985, conhecida como Lei de Ação Civil Pública, que disciplinou a ação civil pública de responsabilidade por danos causados ao meio ambiente; Lei $n^{\circ}$ 8.974/95, Lei de Biossegurança, que estabelece normas de segurança e fiscalização para o uso de técnicas e para a liberação de organismos geneticamente modificados.

A Lei de Propriedade Industrial ou Intelectual, mais conhecida como Lei de Patentes, $\mathrm{n}^{\circ}$ 9.279/96, não abrange o patenteamento de animais e plantas. Contudo, admite o patenteamento de microorganismos transgênicos, caso obtenham os três requisitos de novidade, atividade 
inventiva e aplicação industrial. Possibilita ao titular de uma patente o direito de impedir a terceiros a produção, o uso ou a venda do produto patenteado sem seu consentimento.

Quanto às leis referentes aos direitos indígenas, podemos citar a lei $n^{0}$ 6.001/73, conhecida como Estatuto do Índio, que dispõe sobre as relações do Estado e da sociedade brasileira com os índios. Existe também o Projeto de Lei 2.057/96, Estatuto das Sociedades Indígenas, que regulamenta a Constituição de 1988, no que refere aos direitos das sociedades indígenas. Os objetivos, de maneira geral, estão relacionados à situação legal dos índios e suas comunidades, à proteção aos seus costumes, cultura, incluindo os meios de proteção à herança indígena e à propriedade intelectual.

É possível, com essa breve exemplificação, perceber que a biodiversidade, o conhecimento tradicional e os recursos genéticos ainda não encontram normas e leis suficientemente eficazes para combater a biopirataria. Algumas das razões que facilitam essa prática escusa no contexto brasileiro estão relacionadas à falta de recursos para fiscalização da diversidade biológica, aliada à falta de conscientização de sua importância científico-econômica.

O acordo firmado em 29 de maio de 2000, entre a Bioamazônia e a multinacional Novartis Pharma, comprovou a necessidade de formulação de leis relacionadas à proteção da biodiversidade brasileira. O objetivo do acordo, como apontado por Paulo Péret de Sant'Ana (2002, p. 125), “era coletar, isolar e identificar até 10 mil microorganismos (bactéria e fungos), produzir extratos dos mesmos e realizar análises para identificar substâncias de interesse. A Novartis investiria US\$ 4 milhões em pesquisas, por três anos e repassaria à Bioamazônia 1\% em royalties por produto criado”.

A assinatura desse acordo não teve sequer o conhecimento e a anuência do Ministério do Meio Ambiente. As cláusulas e as condições impostas pela Novartis Pharma tornavam a Bioamazônia apenas uma assistente de transferência física de material genético brasileiro para o aproveitamento comercial exclusivo de seus parceiros. Além de tudo, a Novartis Pharma teria a propriedade de todas as invenções resultantes da pesquisa, até mesmo os compostos diretos e os derivado dessas invenções.

Contudo, foi esse acordo polêmico que precipitou a aprovação da Medida Provisória $\mathrm{n}^{\mathrm{o}} 2.052$ sobre o acesso ao patrimônio genético e ao conhecimento tradicional associado e a repartição de benefícios derivados de sua utilização. Essa Medida Provisória foi reeditada 
sucessivas vezes e, atualmente, encontra-se em vigor a Medida Provisória $n^{0}$ 2.186-16/2001, que dispõe sobre o acesso ao patrimônio genético, a proteção e o acesso ao conhecimento tradicional associado, a repartição de benefícios e a transferência de tecnologia para sua conservação e utilização.

A Medida Provisória 2.186-16/2001 é a melhor garantia de proteção existente no atual contexto brasileiro. $\mathrm{O}$ artigo $8^{\circ}$ reconhece o direito das comunidades indígenas e locais de decidir sobre o uso de seus conhecimentos tradicionais associados ao patrimônio genético, protegendo-os da utilização e da exploração indevida assim como de outras ações lesivas ou não autorizadas pelo Conselho de Gestão do Patrimônio Genético.

O mesmo artigo estabelece algumas garantias às comunidades indígenas e locais que criem, desenvolvam, detenham ou conservem conhecimento tradicional. Ter indicada a origem do acesso ao conhecimento tradicional em todas as publicações, utilizações, explorações e divulgações é apontado como uma das garantias. Impedir terceiros não autorizados à utilização, à realização de testes, pesquisas ou exploração também é um dos objetivos desse artigo.

Compete ao Conselho de Gestão do Patrimônio Genético (CGEN) estabelecer normas técnicas e critérios relacionados à gestão e à autorização de acesso e remessa do patrimônio genético e do conhecimento tradicional associado, assim como estabelecer diretrizes e dar anuência em Contrato de Utilização do Patrimônio Genético e de repartição de benefícios. O CGEN também é responsável pelo estabelecimento de critérios de base para o registro de informações sobre conhecimento tradicional e pelo acompanhamento das atividades de acesso e remessa de amostra de componente do patrimônio genético e de acesso a conhecimento tradicional.

Por fim, o Conselho delibera sobre o credenciamento de instituição pública nacional de pesquisa e desenvolvimento para autorizar outra instituição nacional pública ou privada ou outra instituição sediada no exterior que exerça a atividade de bioprospecção. A instituição pública nacional que servira de fiel depositária também é credenciada de acordo com o CGEN.

A composição do Conselho de Gestão do Patrimônio Genético foi definida pelo decreto $n^{\circ}$ 3.945/2001, que prevê apenas a participação de órgãos e instituições governamentais, não inclui representantes da sociedade civil e das comunidades tradicionais. Isso vem gerando uma série de críticas por parte da sociedade civil. 
Superar o caráter provisório da legislação é um dos maiores desafios para o governo brasileiro, pois somente leis definitivas poderão garantir a atração de investimentos para o país. Contudo, sem essa medida provisória, a situação poderia ser ainda pior.

Nesse contexto, cabe um questionamento: seria necessário reeditar a existente Medida Provisória ou seria suficiente incorporar a ela algumas mudanças técnicas? O Conselho de Gestão do Patrimônio Genético realiza sucessivas reuniões com o objetivo de apresentar novo modelo de lei para o acesso aos recursos genéticos e aos conhecimentos tradicionais associados. A partir dessas reuniões, conceitos e procedimentos técnicos relacionados ao acesso dos recursos genéticos e conhecimentos tradicionais estão sendo especificados e detalhados.

Questões, como quem deverá ser a autoridade competente para autorizar o acesso ao material genético e ao conhecimento tradicional, deverão, segundo o CGEN, ser estabelecidas na lei. Conceitos, como os de comunidade local, não devem fazer referência a temporariedade, ou seja, não devem tratar de conhecimentos transmitidos por sucessivas gerações. Conceitos, como bioprospecção, repartição de benefícios, consentimento prévio fundamentado, também sofreram alterações no novo modelo de lei. A nova proposta apresentará soluções para questões relacionadas ao acesso ao recurso genético, como, se o acesso for realizado em território que apresenta conhecimento tradicional a ele associado e onde, no entanto, os detentores do conhecimento não são proprietários legítimos desse território e sim um particular, haveria divisão dos benefícios entre o proprietário legítimo e os detentores do conhecimento?

É perceptível como a medida provisória existente não abrange todos os pontos importantes. Por isso, novas propostas de lei ou emendas deverão ser encaminhadas ao Congresso Nacional para que ocorra prévio debate sobre a Medida Provisória, antes que esta seja promulgada como lei.

\subsection{Formas alternativas de proteção}

Analisando o sistema vigente de proteção dos conhecimentos tradicionais, fica evidente que este não fornece a proteção necessária. Discute-se, tanto no plano internacional 
quanto no nacional, a necessidade de criação de um regime legal sui generis de proteção aos direitos intelectuais coletivos.

Existem duas visões antagônicas sobre a melhor forma de proteger legalmente os conhecimentos tradicionais. A primeira, proposta pela Organização Mundial de Propriedade Intelectual e defendida, no Brasil, pelo Instituto Nacional de Propriedade Intelectual (INPI), pretende fazer uma adaptação do sistema patentário vigente, protegendo os conhecimentos tradicionais utilizando-se dos mesmos mecanismos legais existentes, tais como, patentes, marcas comerciais, segredos industriais, sem qualquer alteração significativa nos pressupostos conceituais.

A segunda proposta pretende criar um regime legal sui generis, ou seja, totalmente distinto do sistema patentário existente. O sistema sui generis de proteção apresenta:

“características próprias, que incentivem o desenvolvimento sustentável e também possibilitem a proteção do conhecimento ancestralmente adquirido. Tal forma de proteção ainda inexiste, mas necessariamente deve reunir características peculiares, tais como: 1 . ser um direito de propriedade individual ou coletivo, concedido a uma associação [...] ou a toda uma coletividade indeterminada, neste caso, um direito difuso; 2 . não exigir a homogeneidade da espécie ou sua estabilidade, para evitar estímulo à perda da biodiversidade; 3 . incentivar aqueles que conservam organismos vivos, de preferência pequenos e médios conservadores in situ, objetivando, assim, fomentar a participação local, gerando novo instrumento de redistribuição de renda, além de mobilizar recursos humanos, privatizando os custos da conservação da natureza; 4. o direito deve ser inalienável, impenhorável e indivisível, pois também é um direito das gerações futuras, e as gerações presentes não podem perdê-la ou onerá-lo; 5. para o próprio controle do Estado, tal direito deve ser outorgado pelo poder público, mas de forma simplificada e acessível, evitando o grande trâmite burocrático e os altos custos para a solicitação de um registro de propriedade intelectual das formas tradicionais. Seria recomendável a precisão de tempo determinado para a proteção, com renovação no caso da prova da continuidade da conservação.” (VARELLA, 1998, p. 151-152)

A proposta de um sistema sui generis, em outras palavras, parte da constatação de que todo sistema patentário vigente, de proteção de direitos de propriedade intelectual, protege os chamados “conhecimentos novos”, individualmente produzidos, e não os conhecimentos tradicionais, gerados coletivamente e informalmente, transmitidos de geração em geração. Seria necessária, também, a criação de um sistema nacional de registro para garantir os conhecimentos tradicionais associados à biodiversidade. Esse registro deve ser facultativo, gratuito e meramente 
declaratório, não se constituindo condição para o exercício de direitos, mas apenas um meio de prova.

A criação de um banco de dados terá como objetivo principal impedir a biopirataria, isto é, o comércio ilegal da biodiversidade. Alguns países do mundo estão criando bancos de dados digitais sobre sua diversidade biológica e o conhecimento tradicional associado. No Brasil, a primeira iniciativa do gênero é o Núcleo Nacional para Conservação, Proteção e Manejo Sustentável das Plantas Medicinais Brasileiras.

Não foi definido ainda como será o acesso ao banco de dados, no entanto seria necessária uma proteção para defender o conhecimento tradicional de apropriação por outras pessoas além das autorizadas. Pois, com acesso aberto e desprotegido, a repartição de benefícios seria muito mais difícil. Esse banco de dados serviria como meio de prova caso os conhecimentos tradicionais fossem utilizados de forma não prevista em lei. A proteção sui generis oferece a possibilidade de ir além das formas tradicionais do direito de propriedade intelectual e examina outros mecanismos de regulação do acesso aos recursos e de partilha eqüitativa dos benefícios, por isso merece devida elaboração e importância.

\section{UTILIZAÇÃO DA BIODIVERSIDADE}

\subsection{Bioprospecção}

A bioprospecção pode ser definida como método ou forma de localizar, avaliar e explorar sistemática e legalmente a diversidade de vida existente em determinado local e tem como objetivo principal a busca de recursos genéticos e bioquímicos para fins comerciais (SANTOS, 2004). Eventualmente, a bioprospecção pode fazer uso do conhecimento de comunidades indígenas ou tradicionais. Nesse sentido, pode ser entendida como pesquisa de recursos biológicos e genéticos e de conhecimentos tradicionais associados, capazes de proporcionar benefícios para a humanidade, ao mesmo tempo em que aufere valor comercial para as indústrias químicas, farmacêutica, cosmética e alimentar (AZEVEDO, 2002, p. 65). 
É pela etnoprospecção, ou seja, o uso do conhecimento tradicional como fonte de informação, que a bioprospecção tem alcançado melhores resultados. A exploração desses conhecimentos serve como indicador de material apropriado à pesquisa, encurtando a procura dos pesquisadores.

Para a realização e a efetivação da bioprospecção, é necessário que o poder público, as entidades particulares não-governamentais (ONGs), as universidades públicas e particulares, as empresas químicas e farmacêuticas, as comunidades e a coletividade em geral participem por meio de convênios, contratos de concessão, permissão e parcerias. Só assim, poderão ser postos em prática os atos do processo de prospecção da biodiversidade.

O processo de bioprospecção deve observar princípios para que tenha credibilidade científica, política e econômica. Entre os quais, podemos mencionar:

i. O princípio da prevenção, ou seja, o ser humano deve estar atento ao seu meio ambiente e não deve agir sem prévia avaliação das conseqüências.

ii. O princípio da preservação, que deve ser tida como objetivo essencial para que não se esgote o recurso.

iii. O princípio da equidade distributiva, pelo qual os benefícios devem ser partilhados a todos os que participam, especialmente o país proprietário da biodiversidade explorada.

iv. O princípio da participação pública, no qual deverá ser garantida a participação ampla da população envolvida em todos os seus segmentos, por meio de entidades públicas ou particulares e mesmo o cidadão sozinho, pois não cabe apenas ao Estado, enquanto aparelho governamental e administrativo, a obrigação de proteger o meio ambiente; a coletividade não só pode como deve fazê-lo.

v. O princípio da compensação, que deverá observar se a comunidade ou a pessoa fornecedora da matéria-prima ou do conhecimento (por exemplo, os pajés) deve receber compensações em dinheiro ou em bens (SANTOS, 2004).

O processo de bioprospecção passa por três períodos diferentes, desde a concepção até a fase de comercialização de uma nova droga. O primeiro período, conhecido como “descobrimento da droga”, tem início com o desenvolvimento de estratégia adequada para a coleta de amostras biológicas. Esse processo pode ser realizado ao acaso, mas, na maioria das vezes, é conduzido visando ao conhecimento das áreas biomédicas, etnológicas ou ecológicas. Nesse período, são analisadas, obrigatoriamente, a fonte biológica, a localização geográfica, a 
época da coleta e as condições ambientais de cada amostra. Depois de obtidas essas informações, o material coletado passa por procedimentos de screening ${ }^{9}$, para determinar a capacidade de inibir ou de estimular determinadas atividades biológicas relacionadas a doenças ou a processos de curas. Assim, descoberta a sua capacidade, o composto de um extrato biológico passará por uma série de testes envolvendo animais. Se os testes pré-clínicos evidenciarem possível eficácia no tratamento de determinadas doenças, então será feita solicitação ao órgão responsável pela vigilância sanitária, para iniciar testes clínicos em seres humanos.

O segundo período da bioprospecção é conhecido como o de “desenvolvimento da droga”. Ocorrem os testes clínicos em seres humanos com o objetivo de determinar a toxicidade, o valor terapêutico e os efeitos colaterais que a droga pode ter no organismo humano. Se os resultados forem positivos, ou seja, se a nova droga for segura e eficaz, será feita solicitação para o licenciamento comercial ao órgão sanitário regulador competente para aprovação.

No terceiro e último período do processo de bioprospecção, são analisados os aspectos comerciais envolvidos na introdução da nova droga no mercado. A introdução bem sucedida de qualquer novo produto requer pesquisa de mercado, análise de lucratividade, planejamento de produção, marketing e distribuição. Nesse sentido, percebemos como fatores comerciais, institucionais e sociais devem ser considerados integrantes do processo de desenvolvimento de uma nova droga.

A prospecção da biodiversidade deve ser realizada com o intuito de obter os objetivos propostos pela Convenção sobre a Diversidade Biológica: conservação da diversidade biológica, utilização sustentável de seus componentes e repartição justa e eqüitativa dos benefícios derivados da utilização dos recursos genéticos e bioquímicos. Tendo em vista que o Brasil faz parte da citada convenção, o país que tiver acesso à exploração dos elementos da nossa biodiversidade deve proceder à bioprospecção, observando os princípios anteriormente mencionados, principalmente o princípio da repartição de benefícios, que deverá estar previsto em lei.

O Grupo Internacional de Cooperação sobre Biodiversidade (ICGB) ${ }^{10}$ é um exemplo de projeto internacional que utiliza a bioprospecção. Consiste em consórcios financiados pelo governo norte-americano, por meio do Instituto Nacional de Saúde (NIH), da Fundação Nacional

\footnotetext{
${ }^{9}$ Como o próprio nome diz screening é uma espécie de triagem.

${ }^{10}$ INTERNATIONAL COOPERATIVE BIODIVERSITY GROUPS
} 
da Ciência (NSF) e da Agência dos Estados Unidos para o Desenvolvimento Internacional (USAID). Os ICBG lidam com países em desenvolvimento, com diferentes graus de biodiversidade e capacidade técnico-científica instalada, com distintas leis ambientais. Entre os países subdesenvolvidos que fazem parte desse projeto, estão: Argentina, Peru, Chile, Suriname, Costa Rica, México, Camarões e Nigéria.

A parceria, a cooperação e a compensação justa são princípios indispensáveis para manter e usar sustentavelmente a biodiversidade e o conhecimento tradicional. Esse conhecimento, para o ICBG, é tão ameaçado e valioso quanto a diversidade biológica, por isso ambos merecem respeito e devem ser conservados.

Atualmente, os ICBG estão sendo implementados em nove países na América Latina, na África, na Ásia e nas Ilhas do Pacífico. Constrói-se e aprimora-se a capacidade de pesquisa em 20 instituições diferentes e treinam-se centenas de pessoas. Para ter idéia, mais de 5000 espécies de plantas, animais e fungos foram analisados.

A forma de distribuição de benefícios desenvolvida pelos ICBG merece destaque. Todos os benefícios, a curto e longo prazo, retornam às comunidades que colaboraram, tendo ou não utilizado conhecimentos etnomedicinais durante o processo de pesquisa. Cada ICBG é interligado a um fundo consorciado para a conservação e o desenvolvimento de benefícios, visando sempre à melhoria dos serviços de saúde e ao uso sustentável dos recursos locais.

É certo que não podemos acreditar somente no bom senso das empresas interessadas em atividades de bioprospecção. A falta de transferência de tecnologia, recursos financeiros e participação no registro de propriedade intelectual evidenciam que tais acordos, geralmente, não colaboram para o desenvolvimento dos países economicamente pobres, contudo ricos em biodiversidade.

\subsection{Caracterização e análise dos contratos utilizados para recursos genéticos}

Admitindo a importância dos recursos genéticos, é inquestionável que as modalidades de sua coleta sejam objeto de contrato entre, por exemplo, o país fornecedor e o prospector. O instrumento contratual pode ser apontado como um dos escolhidos e promovidos pela CDB para 
atingir o objetivo de conciliar política de desenvolvimento e proteção do meio ambiente. Nesse sentido, uma avaliação dos contratos como modo de estímulo de proteção da diversidade biológica é indispensável.

Analisando os modelos contratuais referentes à utilização de recursos genéticos, verificamos que não existem muitas novidades, e sim aproximação nítida dos contratos clássicos. O contrato de bioprospecção constitui, freqüentemente, a montagem de todas as espécies de contratos existentes. Segundo Bellivier, os principais contratos utilizados como modelos são:

i. os contratos comerciais pelos quais duas ou mais partes se comprometem a trocar dinheiro ou amostras, a fazer ou não alguma coisa para desenvolver a boa prática contratual;

ii. as licenças à propriedade intelectual nos diversos aspectos (propriedade industrial, patentes, segredos comerciais, marcas comerciais);

iii. as licenças ambientais de coleta que não constituem instrumento novo, mas que estão na lógica da CDB;

iv. os contratos de locação imobiliária.

Independente de os contratos sobre recursos genéticos utilizarem os clássicos como modelo, os novos contratos apresentam tipologia própria e estrutura que serão analisadas detalhadamente.

\subsubsection{Tipologia dos contratos sobre os recursos vegetais}

Entre os tipos de contratos sobre recursos genéticos existentes, a distinção entre contrato de acesso (acesso ao material genético no sentido estrito do termo) e contrato de pesquisa (organização de pesquisa científica sobre o material genético coletado) é evidente. Além dessa distinção, existem três formas de contratos sobre recursos genéticos: o contrato de prospecção in situ, o contrato de transferência de um material já coletado e o contrato de uma pesquisa.

O contrato de prospecção in situ considera a pesquisa na natureza dos recursos genéticos e subdivide-se em: 
a) Um simples contrato de pesquisa, que aponta como fase subseqüente à negociação de um acordo comercial. Essa espécie de contrato pode ser chamada de memorandum of understanding (MOU), contrato de pesquisa em parceria ou carta de intenção, em que tudo depende da precisão dos termos e da manifestação de vontade das partes de estarem ligadas pelo documento.

b) Um acordo comercial, no qual as questões de repartição são previstas antecipadamente. O contrato Yellowstone pode ser apresentado como exemplo. Com a assinatura da CDB, a direção do Parque Yellowstone não possibilitou o desenvolvimento de atividades de prospecção sem a aplicação de contratos, prevendo a repartição dos benefícios. Normalmente, o objetivo é desenvolver um remédio.

No contrato de transferência de um material já coletado (material transfer agreement, denominado MTA), há a simples transferência de material de um fornecedor para um beneficiário, com restrições sobre o que pode ser feito com o material recebido. Geralmente, o receptor compromete-se a limitar a utilização que fará do material transferido à pesquisa ou submete o material à outra transferência, ou seja, outro MTA.

Os contratos de organização de uma pesquisa são indispensáveis para compreender como a pesquisa e as indústrias inventam novas regras de cooperação. Subdividem-se em dois tipos:

a) Contrato de uma organização de pesquisa strictu sensu, no qual vários interventores (institutos públicos, empresas privadas, universidades) entram em acordo para analisar um material (uma planta, um genoma, etc.) e um esforço de pesquisa (decifração do genoma, análises químicas, etc.). A cooperação que ocorre é vantajosa, entretanto necessita de regras precisas de acesso ao material estudado e aos resultados que serão alcançados. O contrato impressiona pela possibilidade de conciliar a intenção de trabalhar em cooperação e a manutenção de estímulo para cada um dos parceiros.

b) Contrato para colocar à disposição dados provenientes de uma pesquisa, em que um dos parceiros organiza as condições de acesso aos dados no intuito de passar as informações obtidas ao outro parceiro. É o caso dos contratos Monsanto, nos quais o instituto de pesquisa tem a 
possibilidade de acessar gratuitamente os dados, realizando ou não uma pesquisa comercial; apresentam exclusividade nas pesquisas, podendo ficar com a patente ou com outros títulos de propriedade intelectual no tocante às inovações realizadas. Contudo, o instituto não pode divulgar os dados adquiridos, devendo apresentar um relatório anual à Monsanto, referente ao andamento da pesquisa e, acima de tudo, deve ajustar uma licença mundial não-exclusiva à Monsanto em caso de patente, para que a empresa possa explorar as invenções.

Conhecendo melhor a tipologia desses contratos, torna-se fundamental um estudo detalhado das partes que poderão constituir os contratos sobre os recursos genéticos vegetais. Algumas vezes, o contrato vincula somente duas partes: de um lado, o país fornecedor, ou uma instituição, ou uma comunidade desse país; de outro, a empresa ou o instituto que faz a pesquisa, estuda e desenvolve o produto comercialmente. No entanto, a maioria desses contratos não é limitada à relação entre fornecedor e usuário.

Primeiramente, o Estado (normalmente o do país fornecedor) pode intervir como parte do contrato por meio do Ministério da Agricultura ou do Departamento do Meio Ambiente. Em segundo plano, poderemos ter agentes intercalando-se entre fornecedor e pesquisador (prospector, universidades, etc.). Em terceiro lugar, poderemos ter as ONGs intervindo como partes para representar os interesses de conservação das populações locais.

As cláusulas contratuais são importantes para a formação de qualquer contrato. Nos contratos sobre recursos fitogenéticos, podemos apontar como cláusulas indispensáveis as que tratam sobre:

i. direitos e obrigações que as partes devem ter em relação à prospecção e à pesquisa realizada;

ii. propriedade intelectual, ou seja, qual das partes ficará com os direitos de propriedade intelectual, qual receberá licença ou royalties e qual terá a exclusividade de comercialização, por exemplo;

iii. natureza e montante dos benefícios (benefícios imediatos e a longo prazo, financeiro e não-financeiro, por exemplo);

iv. possíveis beneficiários, ou seja, uma ou várias partes do contrato, o Ministério do Meio Ambiente e, possivelmente, um fundo fiduciário, entre outros.

As comunidades locais podem ser beneficiárias ou partes legítimas desses contratos. Os contratos de recursos genéticos ainda deixam dúvidas quanto, por exemplo, aos benefícios 
esperados, às responsabilidades existentes para cada parte do contrato e ao papel exato dado às populações locais nas estruturas contratuais. Com base nessas dúvidas, tem-se formulado a idéia de criar guias de boas condutas (guidelines) no sentido de orientar a redação de todos os contratos relacionados com recursos vegetais. Enquanto esperamos o desenvolvimento desses guias, contentamo-nos com os contratos existentes como meio de preservar a biodiversidade.

\subsection{Acesso e divisão dos benefícios}

O acesso e a divisão dos benefícios dos recursos genéticos e vegetais têm sido parte dos temas mais debatidos nas negociações da Convenção sobre Diversidade Biológica. Vários artigos da CDB fazem referência a esses aspectos, como: o artigo 15 (acesso aos recursos genéticos); o artigo 16 (acesso para transferência de tecnologia); o artigo 19.1 (participação em pesquisas biotecnológicas sobre recursos genéticos); o 19.2 (acesso aos resultados e benefícios adquiridos de biotecnologias); etc.

A CDB deixa claro, no artigo 15.1, que o acesso aos recursos genéticos será regulamentado por leis nacionais, e a autoridade competente será o governo nacional. Nesse sentido, alguns países já estabeleceram leis nacionais e decisões estaduais contendo regras para o acesso aos recursos genéticos, como Brasil, Índia, Filipinas, Costa Rica, União Africana e os países do Pacto Andino (Bolívia, Colômbia, Peru, Equador e Venezuela). Outros países estão no processo de desenvolvimento de leis nacionais que regulamentam essa questão.

A constatação de que a regulamentação dessa matéria não é tarefa fácil levou o Secretariado da CDB a propor a criação de um grupo de trabalho formado por especialistas em acesso e divisão dos benefícios, denominado $\mathrm{ABS}^{11}$. Um dos produtos desse grupo foram as “diretrizes de Bonn”"12, que orientam o estabelecimento das legislações nacionais, para regular o acesso aos recursos genéticos e a repartição dos benefícios resultantes.

Esse documento traz diretrizes que visam ajudar a elaboração e o desenvolvimento de medidas políticas, legislativas e administrativas sobre acesso aos recursos genéticos. Essas diretrizes recomendam que o sistema de acesso e divisão dos benefícios:

\footnotetext{
${ }^{11}$ Sigla usualmente empregada em inglês significa Access Benefit-Sharing.

${ }^{12}$ Diretrizes de Bonn - Documento acessível em: < www.biodiv.org.br>. Acesso em: 22/02/2006.
} 
- seja baseado em um sistema nacional ou regional sobre a conservação e o uso sustentável da biodiversidade;

- tenha etapas identificadas, esclarecendo quais são as autoridades competentes e os requisitos necessários para obter autorização de acesso; - apresente um sistema de Consentimento Prévio Fundamentado, que envolva todos os atores relevantes e respeite os direitos dos povos indígenas e das comunidades locais;

- seja efetivado por meio de Termos Mutuamente Acordados, que busquem certeza e clareza legal, minimização dos custos de transação, desenvolvimento de diferentes arranjos contratuais para diferentes recursos e diferentes usos e apresente cláusulas mínimas, incluindo as condições para repartição de benefícios (AZEVEDO, 2006).

Os benefícios advindos da utilização dos recursos genéticos podem ser de duas espécies: monetários e não-monetários. Não existem definições oficiais quanto a que benefícios devem surgir da utilização desses recursos. No entanto, as diretrizes de Bonn estipularam quais poderiam ser os benefícios recebidos. Estabeleceram o pagamento de salários, o pagamento de royalties, investimentos em fundos de pesquisa como formas de benefícios monetários. O compartilhamento dos resultados de pesquisas, a colaboração, a cooperação e a contribuição em pesquisas científicas, a participação em desenvolvimento de produtos, as contribuições para a economia local são formas de benefícios não-monetários.

Comumente, participam dos benefícios as organizações governamentais locais, as organizações acadêmicas locais, as comunidades locais, as companhias locais, e as organizações não-governamentais. As organizações governamentais locais recebem, normalmente, pagamento de royalties e, na maioria dos casos, conhecem os resultados das pesquisas e dos desenvolvimentos. As organizações acadêmicas locais (universidades e institutos de pesquisa) recebem diversos benefícios, entre eles, pagamento de royalties, licença de impostos em casos de comercialização, empregos relacionados aos trabalhos de pesquisa, transferência de tecnologia, transferência de informações científicas sobre conservação e uso sustentável da biodiversidade. As comunidades locais recebem uma parte do futuro beneficio monetário na forma de pagamento de royalties, salários pelos serviços e conhecimentos transmitidos. Também recebem apoio para a conservação da biodiversidade. 
Muitos fatores influenciam a divisão dos benefícios, porém não existe instrumento específico que mencione todos os possíveis beneficiários e todas as possíveis formas de benefícios existentes. Nesse sentido, os benefícios devem ser divididos de acordo com a participação dos interessados no desenvolvimento do produto, na conservação da biodiversidade, no desenvolvimento sustentável da pesquisa.

\section{CONCLUSÃO}

Tendo em vista que o Brasil apresenta tão rica biodiversidade, é notável que obter o desenvolvimento sustentável por meio disso é cada vez mais vantajoso. Utilizar conhecimento tradicional associado à biodiversidade é a forma mais eficiente e rápida de alcançar resultados satisfatórios. Assim, compartilhar os benefícios obtidos e oferecer proteção adequada a essa utilização tornou-se imprescindível.

A proteção existente à propriedade intelectual não garante adequadamente os detentores do conhecimento tradicional. Contudo, as formas não-patenteáveis de propriedade intelectual podem ser exploradas para que ocorra a devida proteção.

Outra maneira de reverter a atual forma de exploração dos recursos biológicos por multinacionais é compatibilizar o TRIPS à CDB. Contudo, as tentativas para isso opuseram os países detentores de tecnologia àqueles com vasta diversidade biológica e com populações tradicionais que a utilizam, o que dificulta a compatibilização. Essa situação faz com que consideremos a possibilidade de expansão do acordo TRIPS no intuito de garantir que as patentes possam tornar pública a origem dos recursos genéticos e o uso do conhecimento indígena e considerar formas de garantia da propriedade intelectual sui generis, visando assegurar a partilha eqüitativa de benefícios com as comunidades tradicionais.

Devemos aguardar decisões internacionais para estabelecermos nossas leis? O desenvolvimento de leis brasileiras para essas questões não pode depender de outras regras e normas já estabelecidas. É preciso ser criativo e inovador, afinal nós somos um dos países mais ricos em diversidade biológica. 
No entanto, não podemos permitir que a questão se torne politizada, com contornos ideológicos (como Yankee go home). O assunto é técnico e deve ser tratado assim. Não podemos esquecer que soja, cana de açúcar, café, raças jebuínas, milho, entre outras culturas, são patrimônio genético de outros países. O Brasil tem a economia agrícola baseada nas culturas de exploração. Se fecharmos o acesso ao nosso patrimônio, outros países podem fechar o deles. A biodiversidade é uma questão de interesse geral e não pode ser relegada à mera disputa de interesses particulares e comerciais.

\section{REFERÊNCIAS}

ALBAGLI, S. Geopolítica da biodiversidade. Brasília: Ibama, 1998 citado por PÉRET DE SANT’ANA, Paulo José. A bioprospecção no Brasil: contribuições para uma gestão ética. Brasília: Paralelo 15, 2002.

AZEVEDO, Cristina Maria do Amaral. Acesso aos recursos genéticos: novos arranjos institucionais. Disponível em:

<http://www.anppas.org.br/gt/biodiversidade/Cristina\%20Maria\%20do\%20Amaral\%20 Azevedo.pdf>. Acesso em: 22 fev. 2006.

BELLIVIER, F. Os contratos sobre os recursos genéticos vegetais: tipologia e eficácia. [S.l.: s.n.].

BUENO, Francisco da Silveira. Minidicionário da língua portuguesa. Ed. rev. e atual. Por Helena Bonito C. Pereira, Rena Signer, São Paulo: FTD: LISA, 1996.

EGLER, I. Implementation of the biodiversity convention in Brazil. UK: University East Anglia, 1998. citado por PÉRET DE SANT’ANA, Paulo José. A bioprospecção no Brasil: contribuições para uma gestão ética. Brasília: Paralelo 15, 2002.

INTERNATIONAL COOPERATIVE BIODIVERSITY GROUPS. [Home page]. Bethesda, 2005. Disponível em: <http://www.fic.nih.gov/programs/icbg.html> . Acesso em: 13 dez. 2004.

MANCINI, Rinaldo César. Pior sem ela: lei protege patrimônio genético. Galileu, São Paulo, dez. 2002. 
MINISTÉRIO DO MEIO AMBIENTE. Riqueza de espécies. Brasília, 2006. Disponível em: <http://www. mma.gov.br/port/sbf/chm/biodiv/brasil.html>. Acesso em: 20 fev. 2006.

ORGANIZAÇÃO INTERNACIONAL DO TRABALHO (OIT). Convenção referente a Povos Indígenas e Pessoas Tribais de um país independente, 169. Disponível em <http://www.socioambiental.org/pib/portugues/direito/conv169.shtm.> Acesso em: 20 fev. 2006

PÉRET DE SANT’ANA, Paulo José. A bioprospecção no Brasil: contribuições para uma gestão ética. Brasília: Paralelo 15, 2002.

POSSEY, Darell; DUTFIELD, Graham. Beyond intellectual property: toward traditional resources rights for indigenous peoples and local communities. Canada: International Development Research Centre, 1996.

SANTOS, Antônio Silveira R. dos. Biodiversidade, bioprospecção, conhecimento tradicional e futuro da vida. Revista de Informação e Tecnologia, Campinas, 1994-2001. Disponível em: $<$ http://www.revista. unicamp.br/infotec/artigos/silveira.html >. Acesso em: 10 nov. 2004.

SÃO PAULO (Estado). Secretaria do Meio Ambiente. Convenção da biodiversidade. São Paulo, 1997. p. 16. (Coleção Entendendo o Meio Ambiente, v. 2) citado por PÉRET DE SANT'ANA, Paulo José. A bioprospecção no Brasil: contribuições para uma gestão ética. Brasília: Paralelo 15, 2002.

VARELLA, Marcelo Dias. Viabilização de mecanismos de troca: biodiversidade $\mathrm{x}$ desenvolvimento. São Carlos: UFSC, 1998.

ANEXO 1: Convenção sobre a Diversidade Biológica

Artigo 10 - Utilização Sustentável de Componentes da Diversidade Biológica

Cada parte contratante deve, na medida do possível e conforme o caso:

(c) Proteger e encorajar a utilização costumeira de recursos biológicos de acordo com práticas culturais tradicionais compatíveis com as exigências de conservação ou utilização sustentável.

ANEXO 2: Convenção sobre a Diversidade Biológica

Artigo 18 - Cooperação Técnica e Científica 
4. As partes contratantes devem, em conformidade com a legislação e as políticas nacionais, elaborar e estimular modalidades de cooperação para o desenvolvimento e a utilização de tecnologias, inclusive tecnologias indígenas e tradicionais, para alcançar os objetivos desta convenção. Com esse fim, as partes contratantes devem, também, promover a cooperação para a capacitação de pessoal e o intercâmbio de técnicos.

\section{ANEXO 3: Convenção sobre a Diversidade Biológica}

Artigo 19 - Gestão da Biotecnologia e Distribuição de Seus Benefícios

1. Cada parte contratante deve adotar medidas legislativas, administrativas ou políticas, conforme o caso, para permitir a participação efetiva em atividades de pesquisa biotecnológica das partes contratantes, especialmente países em desenvolvimento, que provêm os recursos genéticos para essa pesquisa e, se possível, nessas partes contratantes.

2. Cada parte contratante deve adotar todas as medidas possíveis para promover e antecipar acesso prioritário, em base justa e eqüitativa das partes contratantes, especialmente países em desenvolvimento, aos resultados e benefícios derivados de biotecnologias baseadas em recursos genéticos providos por essas partes contratantes. Esse acesso deve ser de comum acordo.

3. As partes devem examinar a necessidade e as modalidades de um protocolo que estabeleça procedimentos adequados, inclusive, em especial, a concordância prévia fundamentada, no que respeita à transferência, à manipulação e à utilização seguras de todo organismo vivo modificado pela biotecnologia que possa ter efeito negativo para a conservação e a utilização sustentável da diversidade biológica.

4. Cada parte contratante deve proporcionar, diretamente ou por solicitação, a qualquer pessoa física ou jurídica sob sua jurisdição provedora dos organismos a que se refere o parágrafo $3^{\circ}$ acima, à parte contratante em que esses organismos devam ser introduzidos, todas as informações disponíveis sobre a utilização e as normas de segurança exigidas por essa parte contratante para a manipulação desses organismos, bem como todas as informações disponíveis sobre os potenciais efeitos negativos desses organismos específicos. 


\section{ANEXO 4: Convenção sobre a Diversidade Biológica}

Artigo 8 - Conservação In situ

Cada parte contratante deve, na medida do possível e conforme o caso:

(j) Em conformidade com sua legislação nacional, respeitar, preservar e manter o conhecimento, as inovações e as práticas das comunidades locais e populações indígenas com estilo de vida tradicionais relevantes à conservação e à utilização sustentável da diversidade biológica e incentivar sua mais ampla aplicação com a aprovação e a participação dos detentores desse conhecimento, inovações e práticas; encorajar a repartição eqüitativa dos benefícios oriundos da utilização desse conhecimento, inovações e práticas;

\section{ANEXO 5:}

Acordo sobre os Aspectos dos Direitos de Propriedade Intelectual Relacionado ao Comércio Artigo 27.3(b) - Matéria Patenteável

3. Os membros também podem considerar como não-patenteáveis:

b. plantas e animais, exceto microorganismos e processos essencialmente biológicos para a produção de plantas ou animais, executando-se os processos não biológicos e microbiológicos. Não obstante, os membros concederão proteção a variedades vegetais, seja por meio de patentes, seja por meio de um sistema sui generis eficaz, seja pela combinação de ambos. O disposto neste subparágrafo será revisto quatro anos após a entrada em vigor do Acordo Constitutivo da OMC.

Prismas: Direito, Políticas Públicas e Mundialização http://www.mestrado.uniceub.br/revistamestrado/

Artigo recebido em 15/03/2006 e aceito para publicação em 13/04/2006

A revista Prismas: Direito, Políticas Públicas e Mundialização destina-se à publicação de artigos relacionados com a área jurídica, tem o propósito de difundir as reflexões dos pesquisadores, docentes, discentes, profissionais e estudantes da área de Ciências Jurídicas.

Os artigos são avaliados mediante processo de revisão por pares e deverão contemplar as reflexões que dizem respeito ao estudo do Direito, das Relações Internacionais e das Políticas Públicas. 